\title{
Preparation and in vitro characterization of lamivudine loaded nanoparticles prepared by acid and/or ester terminated PLGA for effective oral anti-retroviral therapy
}

\author{
A. Alper ÖZTÜRK 1 * (D), Gülsel YURTDAŞ KIRIMLIOĞLU 1 (D) \\ 1 Department of Pharmaceutical Technology, Faculty of Pharmacy, Anadolu University, Eskişehir, Turkey. \\ * Corresponding Author. E-mail: aaozturk@anadolu.edu.tr (A.A.Ö.); Tel. +90-222-335 05 80/37 31.
}

Received: 4 March 2019 / Revised: 29 April 2019 / Accepted: 23 May 2019

\begin{abstract}
The aim of this study was to formulate Lamivudine (LAM) loaded poly lactic-co-glycolic acid (PLGA) nanoparticle (NP) formulations by 'double emulsion solvent evaporation' method for oral administration. PLGA with similar molecular weight but two different chemical end-groups (acid or ester terminated), were used in this study to to compare the effects in the characterization of NPs. Particle size (PS), polydispersity index (PDI), zeta potential, entrapment efficiency (EE\%), dissolution and release kinetic studies were carried out for the characterization of NPs and finally for determining the optimum formulation. The selected optimum formulation (B coded) was found to have a PS of $221.0 \pm 0.7 \mathrm{~nm}$ and a low PDI as $0.104 \pm 0.014$. Drug EE \% of optimal NP formulation was found as $30.280 \% \pm 0.600$. In vitro release of LAM loaded NPs were examined in phosphate buffer ( $\mathrm{pH} 6.8$ ). In vitro release studies of LAM-loaded NPs showed an extended release up to 144 hours, thus the demonstration of nanostructures was confirmed. Higuchi and Korsmeyer-Peppas kinetic model was found to fit best for LAM release from PLGA-NPs. The optimum formulation was stable in the 24 -hour gastrointestinal stability study and the NP structure was characterized by DSC, FT-IR and ${ }^{1} \mathrm{H}-$ NMR analyzes. It could be concluded that LAM loaded NPs seem to be a promising extended release drug delivery system for oral administration in antiretroviral therapy. Lastly, in vitro characterization and release data demonstrated the possibility of improved bioavailability of LAM by PLGA-NP formulation and the effect of polymers used in this study on formulation characteristics were also elucidated
\end{abstract}

KEYWORDS: Lamivudine; nanoparticle; PLGA; ester terminated PLGA; acid terminated PLGA; polymer; release kinetics; antiretroviral therapy.

\section{INTRODUCTION}

Lamivudine (LAM) is a potent and effective drug in the group of anti-retroviral drugs prescribed in chronic hepatitis B viruses (HBV) and human immunodeficiency virus (HIV)/ Acquired Immune deficiency Syndrome (AIDS) therapy [1]. It is phosphorylated inside the cell to its active 5'-triphosphate metabolite and then incorporated into viral DNA by HIV reverse transcriptase and HBV polymerase, resulting in DNA chain termination. The pharmacokinetics of LAM are similar in suffer with HBV or HIV infection people and in healthy volunteers [2]. The chemical name and chemical formula of LAM is 4-amino-1-[(2 \{R\},5 \{S\})-2(hydroxymethyl)-1,3-oxathiolan-5-yl]pyrimidin-2-one and $\mathrm{C}_{8} \mathrm{H}_{11} \mathrm{~N}_{3} \mathrm{O}_{3} \mathrm{~S}$, respectively. Figure 1 shown chemical structure of LAM. The drug is rapidly absorbed after oral administration, with maximum serum concentrations usually attained 0.5 to 1.5 hours after the dose. The absolute bioavailability of LAM is approximately 68 and $82 \%$ in children and adults, respectively $[2,3]$.<smiles>Nc1ccn(C2CSC3COC2O3)c(=O)n1</smiles>

Figure 1. Chemical structure of lamivudine.

How to cite this article: Öztürk AA, Yurtdaş Kııımlıoğlu G. Preparation and in vitro characterization of lamivudine loaded nanoparticles prepared by acid and/or ester terminated PLGA for effective oral anti-retroviral therapy. J Res Pharm. 2019; 23(5): 897-913. 
Conventional drug delivery approaches including high active anti-retroviral therapy have increased the quality of life HIV patients. However, an effective drug delivery approach for HIV treatment is still a global problem. Nowadays, due to the limitations of the drug regimens and dosage forms present in anti-retroviral therapy, the virus has a remarkable adaptation capacity. Mononuclear phagocytic system cells, especially monocytes \& macrophages, serve as a reservoir for HIV. For this reason, in addition to organs such as brain, liver and bone marrow, these phagocytic cells must be reached for effective treatment of HIV infection [4]. And also, in anti-retroviral therapy; applications such as frequent dosing, high dose drug administration are among the most common problems of today.

Nanoparticles (NPs) are matrix systems that are prepared by using natural or synthetic polymers with sizes in the range of 10 to 1000 nanometers $(\mathrm{nm})$. NPs, which attract attention of many research groups can be prepared by several methods. The methods used in NP preparation can be designed according to properties such as desired particle size, size distribution and dissolution properties etc. [5]. Nowadays, polymers with controlled biomedical degradation properties have become an important part of tissue engineering and drug delivery therapies. Poly lactic-co-glycolic acid (PLGA) is composed of endogenous and easily degradable lactic and glycolic acid monomers resulting in low toxicity associated with NPs prepared using PLGA. PLGA is one of the most widely used biodegradable polymers and also it is approved by Food and Drug Administration (FDA) and European Medicines Agency (EMA). PLGA is found in different forms depending on the ratio of monomers and those forms can incorporate both hydrophilic and hydrophobic active ingredients providing sustained release profiles for days to years [6]. It is possible to adjust the overall physical properties of the polymer-drug matrix by controlling the relevant parameters such as polymer molecular weight, ratio of lactide to glycolide and drug concentration to obtain a desired dosage and release interval depending on the type of drug [7]. One of the important features for PLGA is end-groups functions. There are three types of end groups in PLGA polymers, which are; the free carboxylic acid, the ester terminated and alkyl ester groups. PLGA capped with ester terminated and alkyl ester groups typically show longer degradation lifetimes than the free acid \& carboxylic analogs [8].

In this study, LAM-loaded PLGA NPs were prepared by 'double emulsion solvent evaporation' method owing to the advantages of PLGA polymer which accepted as the gold standard and double emulsion solvent evaporation method as being economical. This study aims to treat anti-retroviral disease effectively by low dose of LAM in a prolonged release pattern with high bioavailability by using two different PLGA with different end-groups. The effects of this difference on particle size, polydispersity index, zeta potential, entrapment efficiency and dissolution etc. are studied in detail.

\section{RESULT AND DISCUSSION}

\subsection{Preparation of PLGA nanoparticles}

Many polymers and many methods can be used in NP production. Depending on the properties expected from the NP system and the properties of the encapsulated active substance, the polymer and NP production method used in the production of NPs may vary [9]. One of the most important parameters on NP preparation is to select the production method according to the physicochemical properties of the active substance. The solubility of LAM in water is approximately $70 \mathrm{mg} \cdot \mathrm{mL}^{-1}[1,2,3]$. 'Double emulsion solvent evaporation' technique is a very common method used in the entrapment of active substances with high solubility in water. This technique based on double emulsions is commonly used for the entrapment of hydrophilic molecules like LAM, which suffer from low entrapment efficiency because of rapid drug partitioning into the external aqueous phase in classical emulsions. In double emulsification technique, displacement of a lipophilic solvent with a water-miscible semi-polar solvent results in accumulation of polymer on the surface. Rapid diffuse of the nonsolvent reduces the interfacial tension between the two phases leading to an increase in surface area and thus formation of small organic solvent droplets [5]. This method is preferred for the purpose of high entrapment efficiency.

Different types of the same polymer and different end-groups during the chemical synthesis of the same polymer are factors that alter the properties of the NP systems. In this study, two different PLGA polymers with similar molecular weight but with acid end-group (Resomer ${ }^{\circledR}$ RG $504 \mathrm{H}$ ) and ester end-group (PLGA) were used. In order to investigate the effects of chemical end-groups on NPs, 5 different formulations were prepared. The differences between the formulations were determined primarily by preparing formulations containing only Resomer ${ }^{\circledR}$ RG 504 H (A-blank \& A coded formulations) and only PLGA (B-blank \& B coded formulations) followed by preparing formulations containing 1:1 (C-blank \& C coded formulations), 1:2 (D- 
blank \& D coded formulations) and 2:1 (E-blank \& E coded formulations) ratio of polymers. Five different formulations were characterized in detail and the results were discussed.

In the literature, PLGA types used in this study in obtaining LAM loaded NPs were not used in any other study. In a different study, a different type of PLGA [lactide:glycolide 75:25] was used to obtain LAM loaded NPs [10]. The lactide:glycolide ratio of the PLGA types used in our study was 50:50. The PLGA polymer types are all different in their physical and appearance properties and the lactide:glycolide ratio can completely change the properties expected from the formulation. It is also the fact that the device and surfactant used in preparing the formulation changes the properties of the prepared formulation. In addition, our study is comprehensive in terms of solid state characterization realized by DSC, FT-IR and ${ }^{1} \mathrm{H}-\mathrm{NMR}$ study. Different from the literature, release kinetics and gastrointestinal stability study of formulations were evaluated in detail in our study.

\subsection{Characterization study}

\subsubsection{Particle size, Poly dispersity index, Zeta potential}

Adequate characterization of the prepared NP system is of great importance for the development and optimization of well-defined NPs of therapeutic relevance. Determining the particle size (PS), particle size distribution (PDI) and surface charge of NP systems is indispensable for the correct characterization of NPs and is the first preferred characterization method. Dynamic light scattering (DLS) and Zeta potential (ZP) measurements have gained popularity as easy, inexpensive, simple and reproducible instruments for determining PS and surface charge [11]. DLS is preferred in this study because it is the most commonly used technique for accurate estimation of PS and PDI. The results in Table 1 shows the PS and PDI values of PLGA based NPs. The first conspicuous result is that PS increases with encapsulation of LAM and is lower in blank formulations in this study. In literature, it was observed that the formulations containing the active substance had a higher PS than the blank formulations without active substance, and were observed in both different type polymer and PLGA studies $[6,12,13]$. When the PS is examined; it was observed that the C-blank encoded formulation had the lowest PS $(226.0 \pm 5.8 \mathrm{~nm})$ in all blank formulations and the E-coded formulation had the highest PS $(250.1 \pm 3.1 \mathrm{~nm})$ in between active ingredient loaded formulations. As a result, all NPs having a PS of less than $250 \mathrm{~nm}$ were obtained. When the studies done with PLGA were examined, it was observed that 200-300 nm particles were produced especially when the 'Double Emulsification Solvent Evaporation' and 'Spray Drying' techniques were used. The results were consistent with the literature [14]. Also, in this study nanosized particles determined can be attributed to the hydrophobicity of the polymers used. Small PSs were obtained using polymers with high molecular weight and high hydrophobicity due to longer aliphatic chains. It is also conceivable that low PSs are obtained as a result of the mixing speed of 24,000 rpm for 1 minute [15]. In a different LAM-loaded PLGA NP study using Bovine serum albumin (3\%) as the surfactant, higher PSs were obtained [10]. In our study, the use of PVA (0.5 \%) as the surfactant appears to be optimum because of NPs having lower PS are obtained.

Table 1. Particle size, polydispersity index, zeta potential and entrapment efficiency results.

\begin{tabular}{ccccc}
\hline Code & PS $(\mathbf{n m})$ & PDI & ZP (mV) & EE \% \\
\hline A-Blank & $221.3 \pm 4.1$ & $0.089 \pm 0.050$ & $-5.03 \pm 0.52$ & - \\
B-Blank & $216.0 \pm 3.0$ & $0.080 \pm 0.069$ & $-3.75 \pm 0.39$ & - \\
C-Blank & $226.0 \pm 5.8$ & $0.147 \pm 0.023$ & $-3.94 \pm 0.54$ & - \\
D-Blank & $207.1 \pm 0.9$ & $0.091 \pm 0.058$ & $-4.09 \pm 0.19$ & - \\
E-Blank & $216.1 \pm 3.5$ & $0.100 \pm 0.075$ & $-5.93 \pm 0.95$ & - \\
\hline A & $236.7 \pm 1.9$ & $0.177 \pm 0.060$ & $-4.64 \pm 0.14$ & $21.881 \pm 0.917$ \\
B & $221.0 \pm 0.7$ & $0.104 \pm 0.014$ & $-3.65 \pm 0.37$ & $30.280 \pm 0.600$ \\
C & $223.4 \pm 3.8$ & $0.134 \pm 0.053$ & $-4.37 \pm 0.29$ & $25.373 \pm 0.468$ \\
D & $234.2 \pm 0.7$ & $0.198 \pm 0.061$ & $-4.17 \pm 0.38$ & $28.246 \pm 0.531$ \\
E & $250.1 \pm 3.1$ & $0.151 \pm 0.075$ & $-4.63 \pm 0.09$ & $25.705 \pm 0.537$
\end{tabular}

*All results given as (mean \pm SD), PS: Particle size, PDI: Polydispersity index, ZP: Zeta potential, EE \%: Entrapment efficiency, nm: nanometer, $\mathrm{mV}$ : millivolt. 
In relation to the particle size distribution, the parameter used to define the size range of the nanocarrier systems is called the 'polydispersity index' (PDI). The term 'polydispersity' or as suggested by "dispersity" by International Union of Pure and Applied Chemistry (IUPAC) is used to describe the degree of non-uniformity of particle size distribution. PDI is simply a representation of the distribution of size populations within a given sample of NP. The numerical value of PDI ranges from 0.0 (a perfectly similar dispersion in PS) to 1.0 (populations with a very different PS). For polymer-based NP materials, values of less than or equal to 0.2 in practice are considered to be the most widely accepted [16]. In this study, the highest PDI value was observed as $0.198 \pm 0.061$ in the D-coded formulation. The PDI values of the other formulations are very low. According to the literature, very low PDI values of the prepared formulation showed homogeneous particle size distribution [16,17]. Figure 2 presents the reports from Zetasizer Nano ZS, Malvern Instruments. When Figure 2 is carefully examined, it is clear that the prepared NPs have a low PS and a low PDI value.
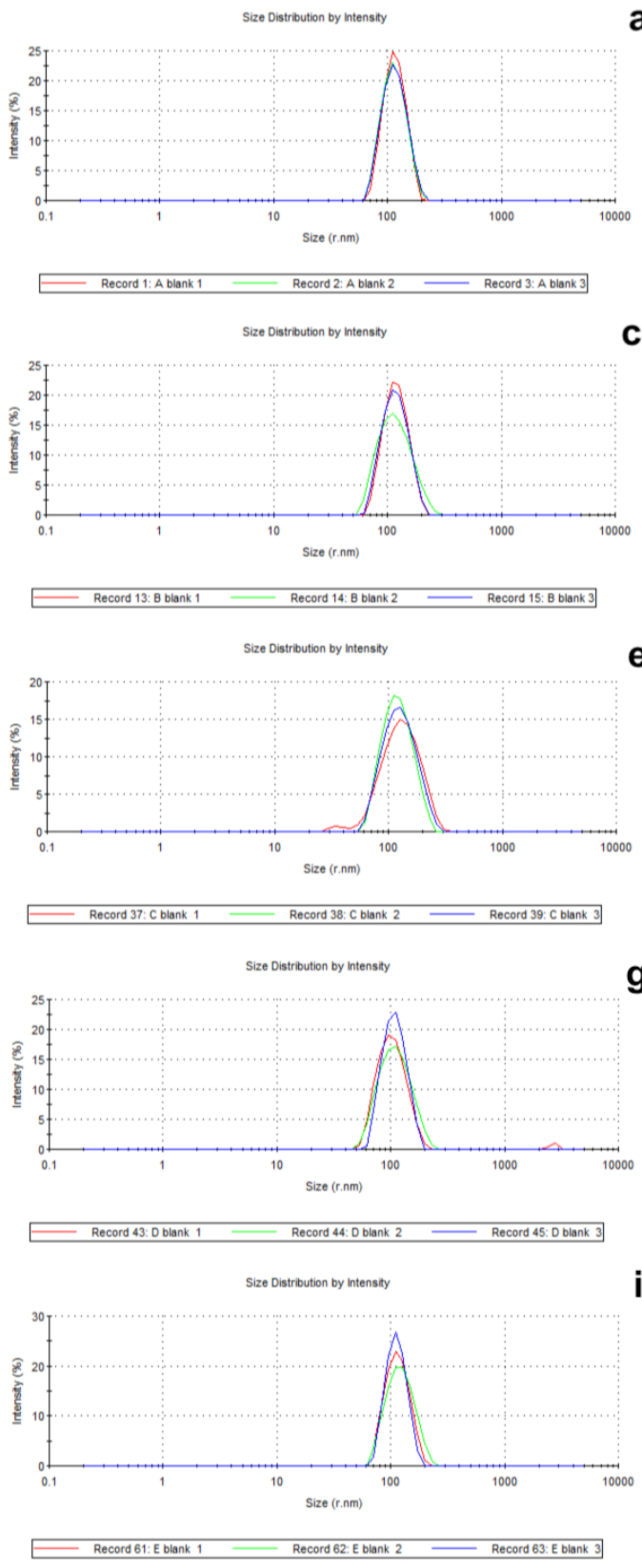

a
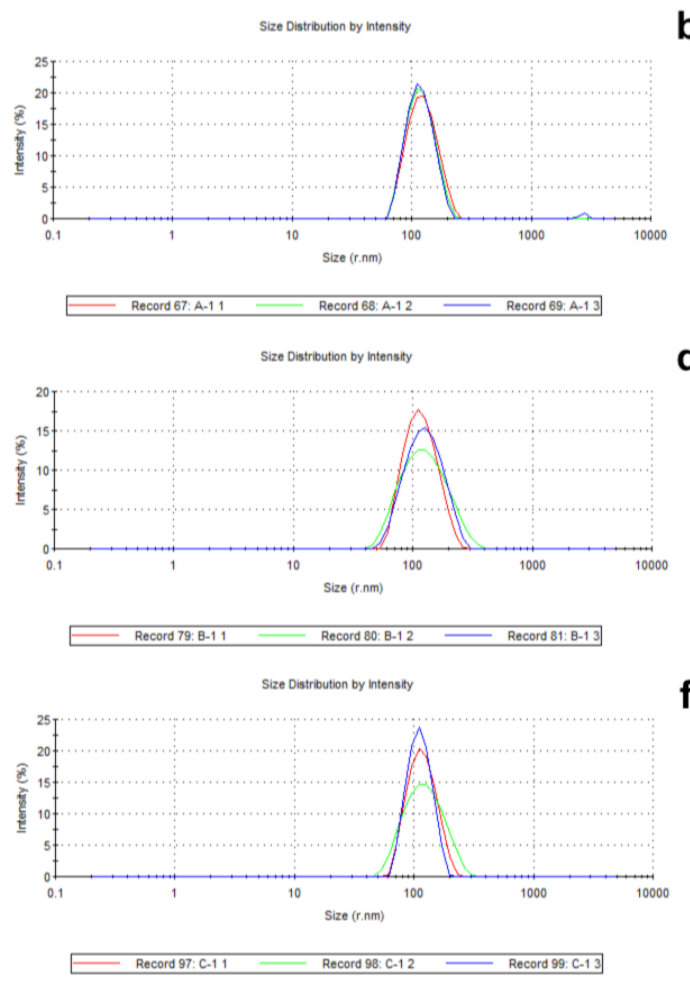

g
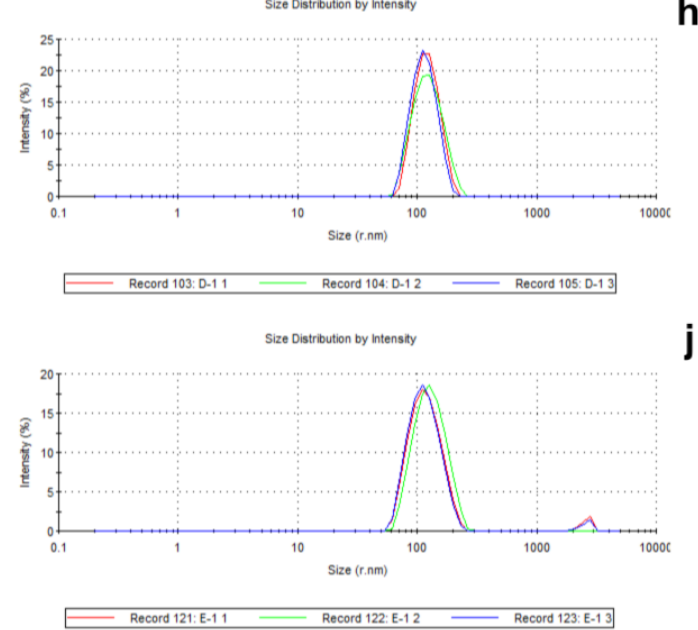

h

Figure 2. Particle size and distribution analysis report a: A-blank, b: A, c: B-blank, d: B, e: C-blank, f: C, g: D-blank, h: D, i: E-blank, j: E. 
Zeta potential (ZP) measurements (based on the electrophoretic mobility of NPs) are widely preferred throughout the world in the characterization of colloidal system. The ZP values of the formulations prepared were presented in Table 1. For the five blank NPs and five LAM loaded NPs samples with different polymer ratios, ZP values were small negative (between -5.93 and -3.65) and almost neutral. The low values and similar ZP values of blank and LAM loaded NPs can be an indication of how the LAM is encapsulated in PLGA NPs, shielded in the polymer not adsorbed at the polymer surface [18]. However, low ZP values are associated with low stability due to the low electrostatic repulsion forces between the NPs. According to this view, the blank and LAM loaded PLGA NPs will have a high tendency of aggregating which in turn compromises the stability of the particles in a formulation [19]. Contrary to this view, very small PDI values $(<0.198 \pm 0.061)$ show that all the samples formed monodispersing in water, a scenario which is impossible in the presence of aggregating. This indicates that NPs are stable despite the very low values of ZP obtained. Because PLGA polymer is a large molecule, stability may be greater due to steric hindrance than surface loading. Also, an adsorbed layer of a polymer or large molecular weight molecule tends to shift plane of shear further from the NPs surface and, as a result, the measured zeta potential decreases. This means that, even in the case of highly charged NPs, a relatively low ZP value can be recorded [20,21]. Also, the negative ZP values can be explained by residual PVA still present on the NP's surface even after three washings and which affects the number of carboxylate group ending [22].

\subsubsection{High Performance Liquid Chromatography (HPLC)}

HPLC method was validated for precision, accuracy and linearity. Linearity of the HPLC method used for the determination of LAM was determined using 9 different concentrations (from $10 \mu \mathrm{g}^{\mathrm{mL}} \mathrm{mL}^{-1}$ to $90 \mu \mathrm{\mu g} . \mathrm{mL}$ ${ }^{1}$ ) and LAM showed a linearity of $y=74791 x+95145\left(r^{2}=0.9999\right)$, accuracy of $100.823 \pm 0.179 \%$ (Mean \pm SD), $100.606 \pm 0.677 \%$ (Mean \pm SD), and $99.857 \pm 0.443 \%$ (Mean \pm SD), for the concentrations of 20, 40 and $60 \mu \mathrm{gg} . \mathrm{mL}^{-}$ 1 , respectively $(n=6)$. Recovery of the method was satisfactory owing to $<2 \%$ RSD value. Limit of detection (LOD) was determined to be $0.1241 \mu \mathrm{g} \cdot \mathrm{mL}^{-1}$ while limit of quantitation (LOQ) was $0.3761 \mu \mathrm{g} \cdot \mathrm{mL}^{-1}$. The method developed for LAM was decided to be precise due to RSD values of $<2 \%$ for repeatability and intermediate precision (for $25 \mu \mathrm{g} \cdot \mathrm{mL}^{-1}, 45 \mu \mathrm{g} \cdot \mathrm{mL}^{-1}, 65 \mu \mathrm{g} \cdot \mathrm{mL}^{-1}$ ). Conclusively, procedure proposed in this study can be used for routine, simultaneous and concurrent LAM determination $[23,24,25]$.

\subsubsection{Entrapment efficiency (EE \%)}

The Entrapment efficiency (EE \%) values of NPs loaded with LAM are given in Table 1. The range of $\mathrm{EE} \%$ of the formulations was from $21 \%$ to $30 \%$. There is a view of an increase of EE \% when the PVA concentration $(\geq 1 \%)$ increases in double emulsion solvent evaporation technique. A possible explanation for this phenomenon is that an increase in PVA concentration may increase the viscosity of the external water phase. In the use of $1 \%$ concentration or more than $1 \%$ of PVA, it increases the diffusion difficulty of the drug to the external water phase, leading to an increased drug retention in the particle and a higher EE \%. However, it was stated that the use of a high percentage of PVA could have a toxic effect even though the formulation was washed. The reason for the low EE \% results (21-30 \%) obtained in the study is thought to be due to the low concentration of PVA (0.5 \%) used as the surfactant. Furthermore, the EE \%, which has a maximum of $30 \%$, may be due to the fact that the precipitation of the PLGA is not fast enough to disperse the drug to the outer aqueous phase during the manufacturing process and due to the diffusion of the LAM to the aqueous phase in the solvent evaporation step. It is known that the amount of drug entrapped within the particles is dependent on the speed of PLGA precipitation from the organic phase. LAM is very soluble in the external aqueous phase. This property coupled with the concentration gradient between the inner and external aqueous phases drives LAM to diffuse into the outer aqueous medium via the organic layer [26].

Drug EE \% of NPs is an important factor in formulations because higher loading leads to lower amount of NPs for a given dose in oral treatment [6]. According to this view, it can be concluded that the B-coded PLGA NP formulation is more suitable for oral treatment.

\subsubsection{Dissolution study}

The pure LAM release profile and LAM release profiles from PLGA NPs were shown in Figure 3. The release of LAM from PLGA NPs continued over 144 hours while pure LAM exhibited a rapid release of $98.344 \% \pm 0.505$ (Mean $\pm \mathrm{SD}$ ) in 24 hour. The release values observed from A, B, C, D, E coded PLGA NP formulations after 144 hours were $63.856 \% \pm 3.581$ (Mean $\pm \mathrm{SD}$ ), $48.506 \% \pm 1.257$ (Mean $\pm \mathrm{SD}$ ), $55.148 \% \pm 1.731$ 
$($ Mean \pm SD), $54.284 \% \pm 2.460$ (Mean \pm SD) and $\% 59.217 \pm 3.334$, respectively, demonstrating extended release from all formulations, relative to pure LAM.
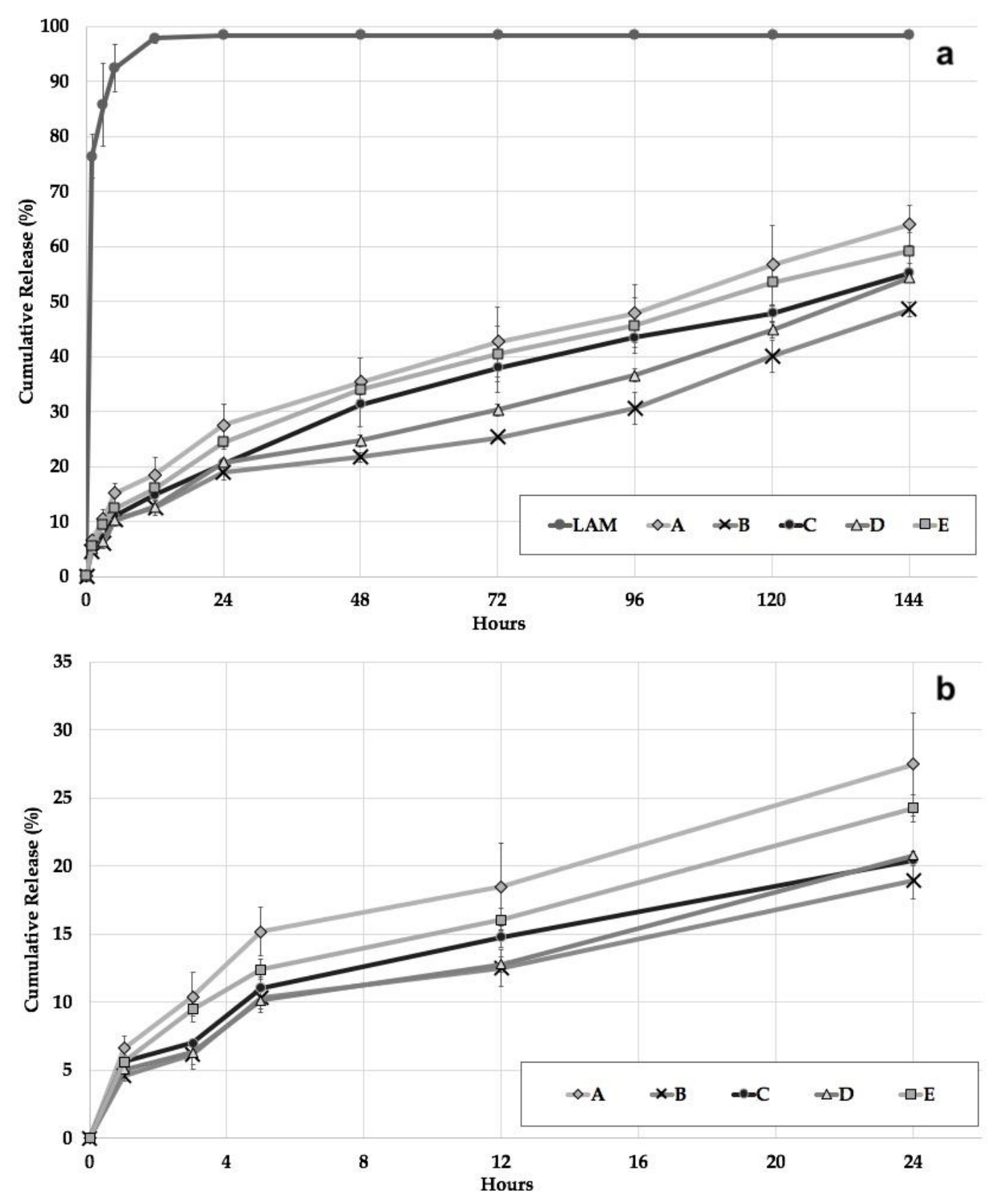

Figure 3. In vitro dissolution profile of lamivudine (LAM) and LAM-loaded PLGA NPs, a: 144 hours profile, b: 24 hours profile.

When literature search is performed, biphasic release is observed in NP systems prepared with PLGA polymer. The PLGA copolymer is first degraded by hydrolysis or biodegradation by dividing backbone ester linkages to oligomers and then into monomers. Therefore, a biphasic curve for drug release as a result of PLGA biodegradation has been shown to display following pattern: initial burst effect and long second phase [7]. It has been reported that drug release rate is initially controlled by diffusion followed by degradation/erosion [13]. When the results of the dissolution study were examined, a rapid release was observed up to 24 hours. Cumulative release rates with burst release at the 24th hour of A, B, C, D, E coded formulations were found as follows; $27.494 \% \pm 3.802$ (Mean \pm SD), $18.983 \% \pm 1.404$ (Mean \pm SD), $20.445 \% \pm 0.400$ (Mean \pm SD), 
$20.785 \% \pm 0.323$ (Mean \pm SD), $24.261 \% \pm 0.999$ (Mean \pm SD), respectively. The rapid release of these formulations was finished at the end of the 24th hour and passed to their second phase, which was slow release. The most important factor that draws attention here is that the release rates in the first phase (burst effect) were found as $\mathrm{A}>\mathrm{E}>\mathrm{D}>\mathrm{C}>\mathrm{B}$ and $\mathrm{A}>\mathrm{E}>\mathrm{C}>\mathrm{D}>\mathrm{B}$ was observed at the end of 144 hours. These different release rates of the formulations prepared using the polymer of similar molecular weight are the answer to the effect of the type of polymer, one of the main purposes of the study, on the formulation. One of the important features for PLGA is end-groups functions. Three types of PLGA polymers can be found in the end-group, which are; the free carboxylic acid group, the ester terminated group, the alkyl ester group. PLGA capped with ester terminated and alkyl ester groups typically show longer degradation lifetimes than the free carboxylic analogs [8]. According to the other formulations, the A-coded formulation had a maximum burst effect of up to 24 hours and a maximum release rate at the end of 144 hours. In the B-coded formulation, this is the exact opposite. C, $\mathrm{D}$, E coded formulations; showed different release properties according to the polymer ratio used in the formulation. The B-coded formulation was prepared only with the polymer having the end-group of esters (slow release) and A-coded formulation was prepared only with the polymer having the end-group of acids (fast release). In this study, the effect of chemical end-groups on the release study of the polymer used was quite clear. As a total result, it was found that LAM entrapped in PLGA-NP was released in a sustained pattern.

In literature, the study in which LAM-loaded PLGA NPs were prepared, an obvious burst release was observed during the first 2 hours, and then the release was slowed down and reached to a plateau after 8 hours, during which about $60 \%$ of the drug was released at $\mathrm{pH}$ 7.4. These researchers have stated that this high rate of burst effect is caused by the LAM molecules that are adsorbed or located near the particle surface [10]. In our study, when the release rates of 144 hours were examined, it is the fact that the extended release formulations were prepared more successfully than the previous study.

\subsubsection{Kinetic analysis of dissolution data}

Kinetic modeling of LAM release from PLGA NPs is shown in Table 2. After obtaining the release profiles, data were transferred to the DDSolver program to determine the five most important and popular criteria: coefficient of determination (Rsqr, $\mathrm{R}^{2}$, or COD), adjusted coefficient of determination (Rsqr_adj or $\mathrm{R}^{2}$ adjusted), Akaike Information Criterion (AIC), Model Selection Criterion (MSC) and release exponent (n). The MSC provided by Micro Math Corporation is a statistical criterion for model selection which is attracting increasing attention in the field of dissolution data modeling. The AIC has been used for selecting optimal models for more than 35 years. Its general simplicity and applicability make it a perfect and popular criterion for various purposes, including drug dissolution analysis. The MSC is a modified reciprocal form of the AIC and has been normalized so that it is independent of the scaling of the data points [27]. The highest $\mathrm{R}^{2}, \mathrm{R}^{2}$ adjusted and MSC values and the lowest AIC values were used for evaluating zero-order kinetics, first-order kinetics, Higuchi, Korsmeyer-Peppas, Hixson-Crowell and Hopfenberg models $[6,13,27]$. The $\mathrm{R}^{2}$ and $\mathrm{R}^{2}$ adjusted values for the zero-order kinetics, first-order kinetics, Hixson-Crowell, Hopfenberg are smaller than other model for all NPs, which are relatively small. This suggests the drug release does not comply with zero-order kinetics, first-order kinetics, Hixson-Crowell and Hopfenberg model. Table 2 shows the release exponent $(n)$ and other values for PLGA NPs obtained by fitting the drug-release profiles to Korsmeyer-Peppas and Higuchi models of drug. The $n$ values of $0.462,0.457,0.475,0.473$ and 0.467 for A, B, C, D and E coded PLGA NP, respectively, indicate the drug release follows an Non-Fickian diffusion mechanism $(0.45<n<0.89)$. Thus, the release of LAM from the matrix of PLGA is diffusion controlled $[28,29]$. And also, depending on the $\mathrm{R}^{2}, \mathrm{R}^{2}$ adjusted, MSC and AIC values obtained, Higuchi and Korsmeyer-Peppas models were found to be more suitable than the other release kinetics [13,30]. Automatic reports from the DDS program are presented in Figure 4. Figure 4 shows the predicted and observed release for all NPs, and the releases have proven to be compatible with Higuchi and Korsmeyer-Peppas models. 

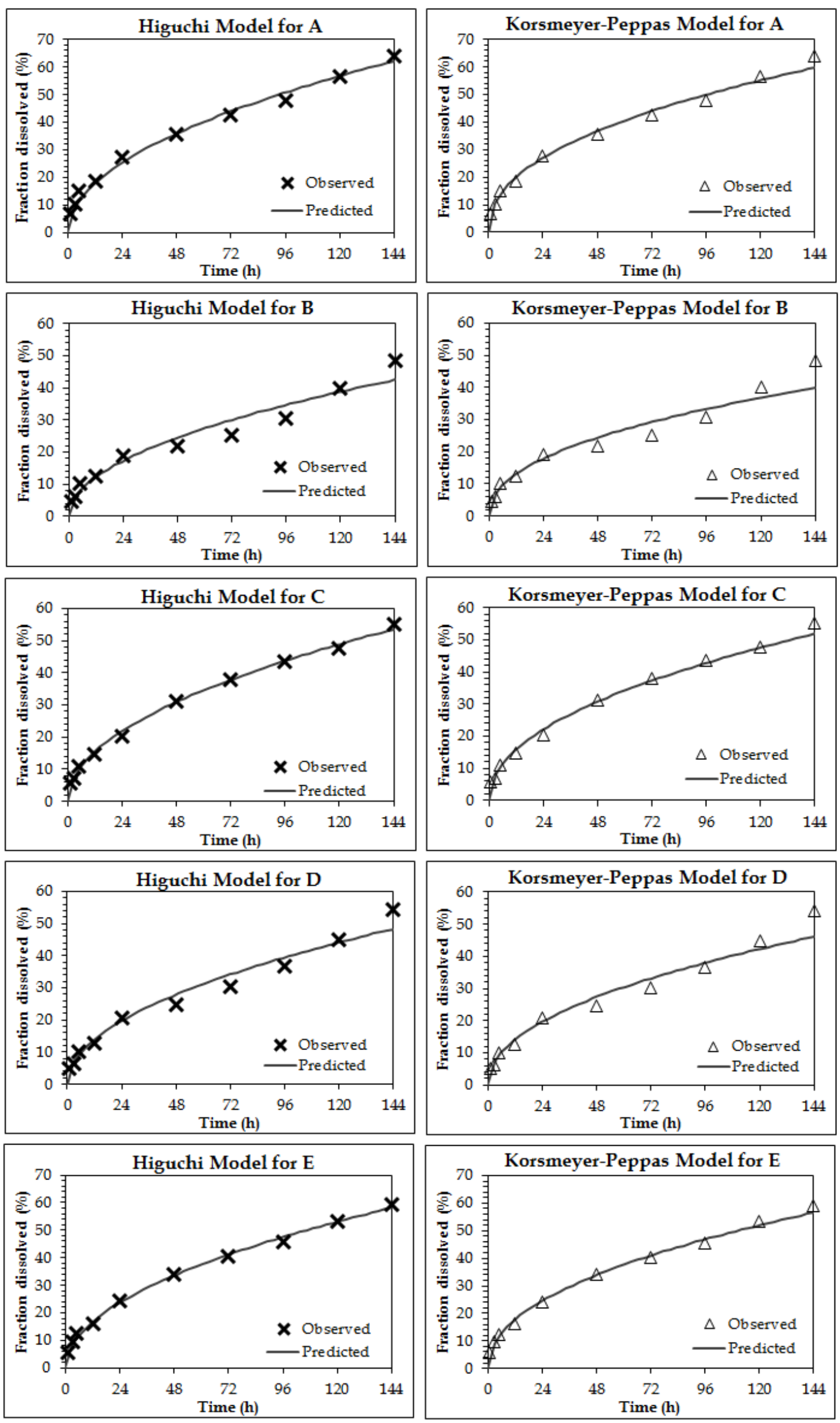

Figure 4. Release kinetics results received automatically from the DDSolver program. 
Table 2. Release kinetic modelling and results of PLGA nanoparticules.

\begin{tabular}{|c|c|c|c|c|c|c|}
\hline \multirow[b]{2}{*}{ Model and Equation } & \multirow[b]{2}{*}{ Code } & \multicolumn{4}{|c|}{ Evaluation Criteria } & \multirow[b]{2}{*}{$n$} \\
\hline & & $\mathbf{R}^{2}$ & $\mathbf{R}_{\text {adjusted }}$ & AIC & MSC & \\
\hline \multirow{5}{*}{$\begin{array}{c}\text { Zero-order* } \\
\qquad \mathrm{F}=\mathrm{k}_{0} * \mathrm{t}\end{array}$} & $\mathbf{A}$ & 0.742 & 0.742 & 70.323 & 1.154 & - \\
\hline & B & 0.822 & 0.822 & 60.256 & 1.523 & - \\
\hline & $\mathrm{C}$ & 0.809 & 0.809 & 65.289 & 1.454 & - \\
\hline & D & 0.859 & 0.859 & 60.821 & 1.762 & - \\
\hline & $\mathrm{E}$ & 0.781 & 0.781 & 67.862 & 1.321 & - \\
\hline \multirow{5}{*}{$\begin{array}{c}\text { First-order* } \\
\mathrm{F}=100^{*}\left[1-\operatorname{Exp}\left(-\mathrm{k}_{1}{ }^{*} \mathrm{t}\right)\right]\end{array}$} & $\mathbf{A}$ & 0.854 & 0.854 & 64.588 & 1.727 & - \\
\hline & B & 0.858 & 0.858 & 57.992 & 1.750 & - \\
\hline & C & 0.896 & 0.896 & 59.238 & 2.059 & - \\
\hline & D & 0.903 & 0.903 & 57.058 & 2.138 & - \\
\hline & $\mathrm{E}$ & 0.882 & 0.882 & 61.718 & 1.935 & - \\
\hline \multirow{5}{*}{$\begin{array}{l}\text { Higuchi }^{*} \\
\mathrm{~F}=\mathrm{k}_{\mathrm{H}}^{*} \mathrm{t}^{0.5}\end{array}$} & $\mathbf{A}$ & 0.990 & 0.990 & 37.557 & 4.430 & - \\
\hline & B & 0.950 & 0.950 & 47.484 & 2.801 & - \\
\hline & C & 0.997 & 0.997 & 24.611 & 5.522 & - \\
\hline & D & 0.971 & 0.971 & 45.096 & 3.334 & - \\
\hline & $\mathrm{E}$ & 0.997 & 0.997 & 25.179 & 5.589 & - \\
\hline \multirow{5}{*}{$\begin{array}{c}\text { Korsmeyer-Peppas* } \\
\qquad \mathrm{F}=\mathrm{k}_{K P}{ }^{*} \mathrm{t}^{\mathrm{n}}\end{array}$} & A & 0.991 & 0.990 & 38.665 & 4.320 & 0.462 \\
\hline & B & 0.937 & 0.930 & 51.766 & 2.373 & 0.457 \\
\hline & C & 0.994 & 0.993 & 33.162 & 4.666 & 0.475 \\
\hline & D & 0.992 & 0.957 & 49.750 & 2.869 & 0.473 \\
\hline & $\mathrm{E}$ & 0.996 & 0.995 & 30.089 & 5.098 & 0.467 \\
\hline \multirow{5}{*}{$\begin{array}{l}\text { Hixson-Crowell } \\
F=100^{*}\left[1-\left(1-k_{H C}{ }^{*}\right)^{3}\right]\end{array}$} & $\mathbf{A}$ & 0.824 & 0.824 & 66.485 & 1.538 & - \\
\hline & B & 0.848 & 0.848 & 58.681 & 1.681 & - \\
\hline & C & 0.872 & 0.872 & 61.276 & 1.855 & - \\
\hline & D & 0.892 & 0.892 & 58.212 & 2.023 & - \\
\hline & $\mathrm{E}$ & 0.885 & 0.885 & 63.776 & 1.730 & - \\
\hline \multirow{5}{*}{$\begin{array}{c}\text { Hopfenberg* } \\
F=100^{*}\left[1-\left(1-k_{H B}{ }^{*} t\right)^{n}\right]\end{array}$} & A & 0.824 & 0.802 & 68.485 & 1.338 & - \\
\hline & B & 0.848 & 0.829 & 60.681 & 1.481 & - \\
\hline & C & 0.872 & 0.856 & 63.276 & 1.655 & - \\
\hline & D & 0.892 & 0.878 & 60.212 & 1.823 & - \\
\hline & $E$ & 0.885 & 0.837 & 65.776 & 1.530 & - \\
\hline
\end{tabular}

*In all models, $\mathbf{F}$ is the fraction (\%) of drug released in time $\mathbf{t}, \mathbf{k}_{\mathbf{0}}$ : zero-order release constant, $\mathbf{k}_{1}$ : first-order release constant, $\mathbf{k}_{\mathrm{H}}$ : Higuchi release constant, $\mathbf{k}_{\mathrm{KP}}$ : release constant incorporating structural and geometric characteristics of the drugdosage form, $\mathbf{n}$ : is the diffusional exponent indicating the drug-release mechanism, $\mathbf{k}_{\mathrm{HC}}$ : Hixson-Crowell release constant, $\mathbf{k}_{\mathrm{HB}}$ : Hopfenberg release constant.

\subsection{Optimum formulation selection and characterization}

After the preparation of 5 different blank formulations and 5 different active ingredient loaded formulations prepared with PLGA type having two different end-groups, detailed characterization was done and the results were discussed. PS, PDI, ZP, EE \%, dissolution and release kinetics properties were taken into account for optimum formulation selection. B-coded formulation is optimally selected, because it has a lower PS and PDI value and higher EE \%, which reduces the amount of NP to be administered to the patient. 


\subsubsection{Evaluation gastrointestinal stability of PLGA nanoparticles}

PLGA NPs composed of hydrolytic degradable polymers are known to degrade over time. It was reported that temperature and $\mathrm{pH}$ have very significant effects on long-term stability of drugs [15]. Figure 5 shows NP's PS and PDI in pH 1.2 buffer, intestinal fluid phosphate buffer solution (pH 6.8), phosphate buffer solution ( $\mathrm{pH}$ 7.4), physiological serum $(\mathrm{NaCl} 0.9 \%$ ) and distilled water. Mean PS of B-coded NPs kept at 37 ${ }^{\circ} \mathrm{C}$ for $24 \mathrm{~h}$ in $\mathrm{pH} 1.2$ buffer and distilled water were determined to increase significantly in comparison to corresponding values of the freshly prepared NPs $(221.0 \pm 0.7 \mathrm{~nm}$, for B coded PLGA NP, Mean \pm SD). On the other hand, PS values in intestinal fluid phosphate buffer solution $(\mathrm{pH} 6.8)$, phosphate buffer solution $(\mathrm{pH}$ 7.4), physiological serum $(\mathrm{NaCl} 0.9 \%)$ demonstrated relatively reasonable results indicating lower degradation of NP in those media, especially after 3rd hour. The results obtained indicate slow degradation of NPs in phosphate buffer solution ( $\mathrm{pH}$ 6.8), phosphate buffer solution ( $\mathrm{pH} 7.4)$, physiological serum $(\mathrm{NaCl}$ $0.9 \%$ ) solution media at $37^{\circ} \mathrm{C}$ which has shown that it is stable in these media and that it should be an intestinal targeted drug delivery system. The results obtained indicate slow degradation of NPs in these media at $37^{\circ} \mathrm{C}$, which also provides preliminary information for selection of dissolution medium [6].
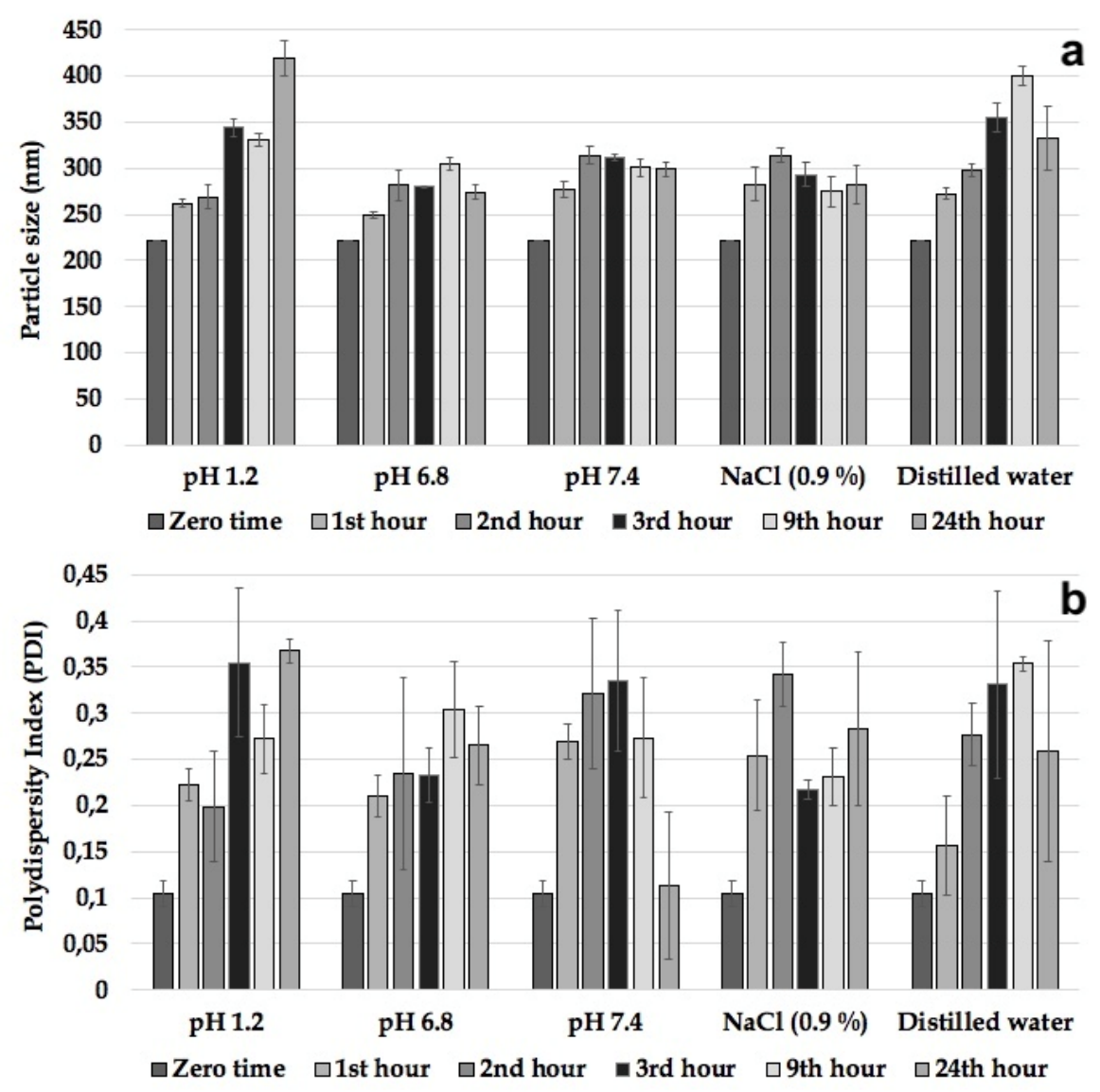

Figure 5. Gastrointestinal stability study in different media, a: Particle size b: Polydispersity index.

\subsubsection{Thermal analysis (DSC)}

DSC results of pure LAM, B-Blank and B-coded PLGA NPs obtained in the determination of the physical state of LAM in NPs are given in Figure 6. DSC curve of LAM (Figure 6-a) showed a sharp endothermic peak at $181.21^{\circ} \mathrm{C}$. This endothermic peak of LAM was consistent with the literature [31]. The endothermic peak of B-blank and B coded formulation is observed at $50.66^{\circ} \mathrm{C}$ and $50.60^{\circ} \mathrm{C}$, which can be attributed to the glasstransition temperature of PLGA [32]. DSC curve of B-coded PLGA NP formulation demonstrated disappearance of the sharp endothermic LAM peak at $181.21^{\circ} \mathrm{C}$. Complete disappearance of active substance peak may be due to either the homogeneous polymeric matrix formation or to the dilution effect of the polymer [33]. Disappearance of endothermic LAM peak in DSC curves of NPs prepared indicated incorporation of LAM, homogenous matrix formation and amorphous structure and also loss of drug crystallinity [13, 34]. 

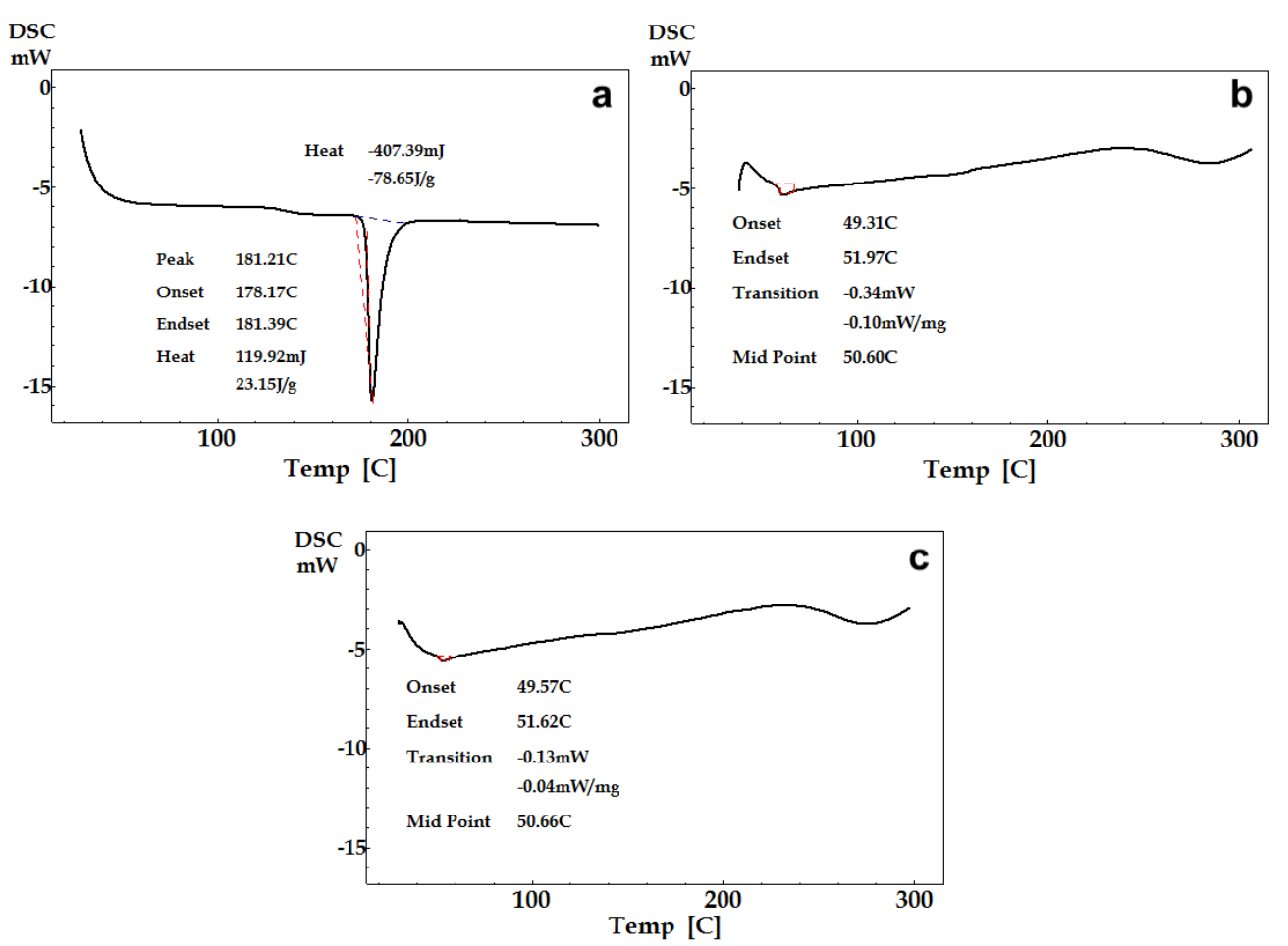

Figure 6. DSC curves of lamivudine and formulations, a: LAM, b: B-Blank, c: B.

\subsubsection{FT-IR analysis}

FT-IR analyses were shown to be important tools to quickly obtain information about possible interactions between the active agents and polymers [35]. The FT-IR spectrum of LAM (Figure 7-a) showed characteristic peak of the carbonyl group present in the cytidine nucleus at $1494.83 \mathrm{~cm}^{-1}$ and peaks at 1286.52 $\mathrm{cm}^{-1}$ and around $1160 \mathrm{~cm}^{-1}$ due to asymmetrical and symmetrical stretching of the C-O-C system of oxathiolane ring [36]. In blank formulation (B-blank) and LAM loaded formulation (B) medium intensity bands between $1450-1200 \mathrm{~cm}^{-1}$ were attributed to asymmetric and symmetric $\mathrm{C}-\mathrm{C}(=\mathrm{O})-\mathrm{O}$ stretches from PLGA polymer, respectively. In addition, $\mathrm{C}-\mathrm{O}$ stretches and $\mathrm{C}-\mathrm{H}$ bends were observed in the formulations between 1200-1050 $\mathrm{cm}^{-1}$ and 1450-850 $\mathrm{cm}^{-1}$, respectively. These stretches and bends were attributable to the PLGA [37]. No chemical interaction between PLGA and LAM could be found due to the absence of new LAM peaks in FTIR spectra of PLGA-NP. It was observed that the characteristic LAM peaks were disappeared and LAM crystallinity was decreased for B-coded formulation (Figure 7-c) [13]. This indicated that LAM is molecularly dispersed and encapsulated in the polymeric structure supporting DSC results [30].

\subsection{5. ${ }^{1} \mathrm{H}-\mathrm{NMR}$ analysis}

Since the substances and formulations are dissolved in deuterated solvents in the NMR analysis, the peaks of all substances can be easily observed. Intermolecular interactions between LAM \& PLGA and entrapment of LAM to NPs were evaluated in this study also by ${ }^{1} \mathrm{H}-\mathrm{NMR}$ [35]. It is known that PLGA contains two types of structural units: the most intense signals of $\mathrm{CH}(4.8-5.2 \mathrm{ppm})$ and $\mathrm{CH}_{3}(1.5 \mathrm{ppm})$ from lactic acid and $\mathrm{CH}_{2}(4.88 \mathrm{ppm})$ from glycolic acid. The $\mathrm{CH}_{2}$ hydrogens were diastrophic and divided into two, ending in two pairs of peaks which were assigned for both protons. Higher $\mathrm{CH}_{2}, \mathrm{CH}_{3}$ and $\mathrm{CH}$ signals in the copolymer caused those peaks to expand [15]. When the ${ }^{1} \mathrm{H}-\mathrm{NMR}$ analyzes of B-Blank and B-coded formulations were examined (Figure $8 \mathrm{~b}-\mathrm{c}$ ); the peaks in these ppm values can be attributed to the PLGA polymer. Specific peaks of LAM in ${ }^{1} \mathrm{H}-\mathrm{NMR}$ spectrum (Figure 8-a) were observed at $7.83 \mathrm{ppm}(\mathrm{dd}, 1 \mathrm{H}), 7.17 \sim 7.23 \mathrm{ppm}(\mathrm{dd}, 2 \mathrm{H}), 6.21$ ppm $(\mathrm{t}, 1 \mathrm{H}), 3.32 \sim 3.43 \mathrm{ppm}(\mathrm{dd}, 1 \mathrm{H}), 3.01 \sim 3.15 \mathrm{ppm}(\mathrm{dd}, 1 \mathrm{H})$ [38]. Specific LAM peaks in the spectra of LAM loaded PLGA NP (Figure 8-c) suggest LAM incorporation into PLGA polymer, as well as molecular distribution of LAM into the polymeric matrix [15]. 


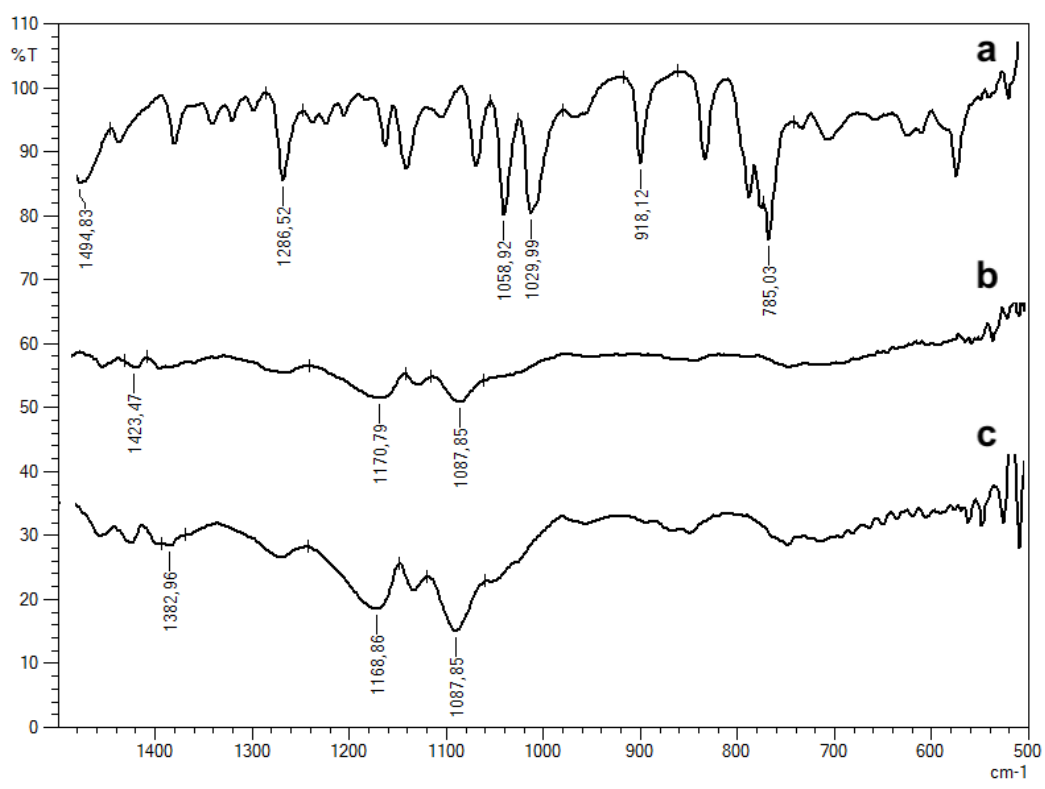

Figure 7. FT-IR analysis of lamivudine and formulations a: LAM, b: B-Blank, c: B, $* \%$ T: transmittance $\%$.

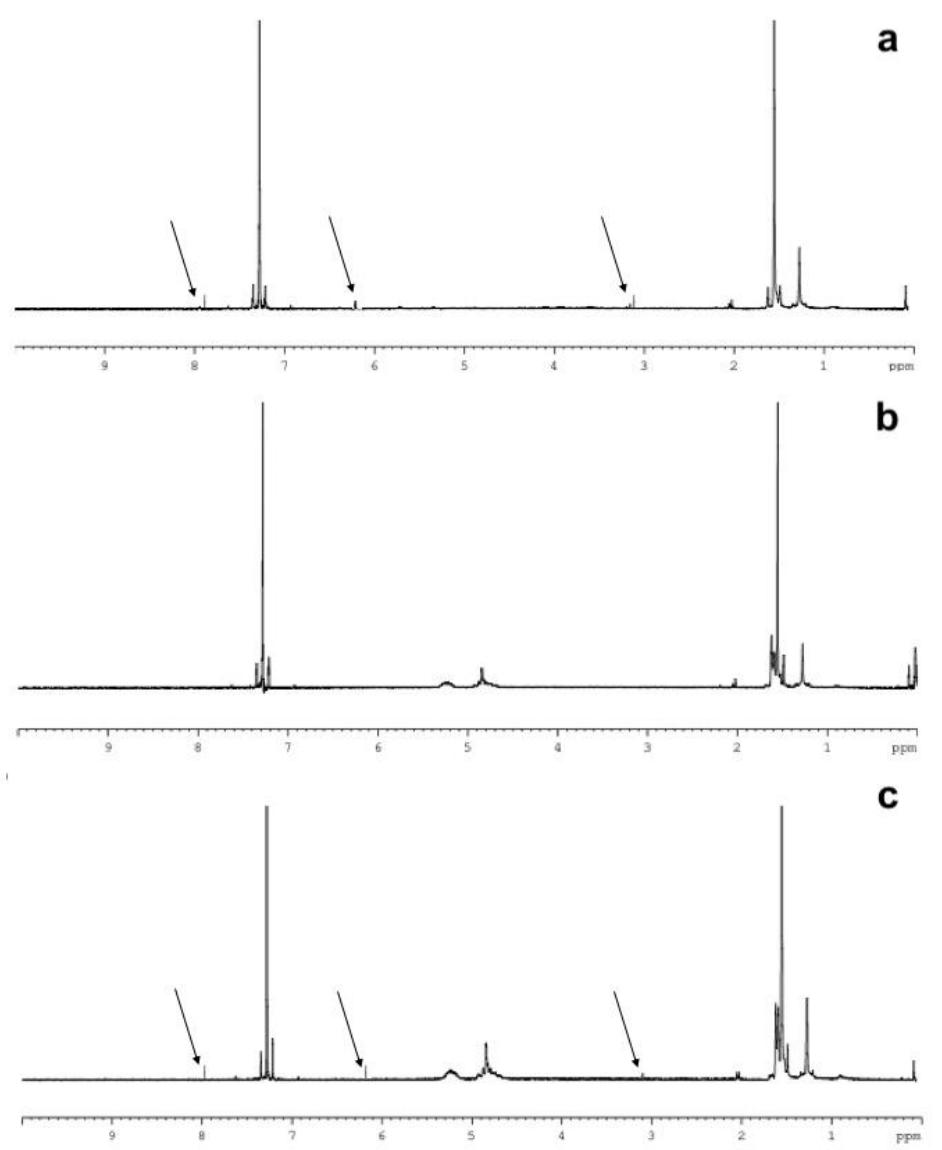

Figure 8. ${ }^{1} \mathrm{H}-\mathrm{NMR}$ analysis of lamivudine and formulations, a: LAM, b: B-Blank, c: B. 


\section{CONCLUSION}

We have successfully formulated, lamivudine loaded biodegradable PLGA nanoparticles by double emulsification solvent evaporation technique. The formulations have a low particle size and are highly monodisperse. The release of lamivudine from the particles was firstly with burst effect. The release was then slow and prolonged. Higuchi and Korsmeyer-Peppas models were found to be most suitable models. The particle size of nanoparticle formulation remained constant in the nanometer range in the short-term gastrointestinal stability test. The physical state studies confirmed the decrease of drug crystallinity in the nanoparticles. The intermolecular interaction between lamivudine and PLGA was identified in the DSC, FTIR and ${ }^{1} \mathrm{H}-\mathrm{NMR}$ analysis of the nanoparticles. PLGA with similar molecular weight but two different chemical end-groups (acid or ester terminated), were used in this study to compare the effects in the characterization of NPs. These end groups, were effected NPs properties, especially EE\% and Release rates. The NP prepared with the polymer having the ester end-group showed slow release, whereas the NP with only the acid endgroup showed rapid release. The discovery of such differences is one of the most important innovative aspects of this study. Our approach to formulating lamivudine loaded nanoparticles, with stable physicochemical properties, offers the potential of further developing novel nanoparticles formulation for use anti-retroviral treatments such as in chronic hepatitis B, HIV \& AIDS. Hence it could be concluded that lamivudine loaded nanoparticles seem to be a promising delivery system for the oral application. On the other hand, using cellular and animal models of viral infection analysis results are needed to make the final decision and use in clinic.

\section{MATERIALS AND METHODS}

Lamivudine was provided as a gift sample from SANOVEL, Istanbul, Turkey. Resomer ${ }^{\circledR}$ RG $504 \mathrm{H}$ [Poly(D,L-lactide-co-glycolide), acid terminated, lactide:glycolide 50:50, Mw 38.000-54.000] and PLGA [Poly(D,L-lactide-co-glycolide), ester terminated, lactide:glycolide 50:50, Mw 30.000-60.000] was purchased from Sigma-Aldrich, Germany. All other chemicals used were of analytical grade.

\subsection{Preparation of PLGA nanoparticles}

PLGA NPs were prepared by 'Double Emulsification Solvent Evaporation Technique' [14]. Firstly, accurately weighed amount of PLGA $(60 \mathrm{mg})$ was dissolved in $2 \mathrm{~mL}$ ethyl acetate. $100 \mu \mathrm{L}$ aqueous solution of PVA $(0.5 \% \mathrm{w} / \mathrm{v})$ was added drop-wise to $2 \mathrm{~mL}$ PLGA solution using ultrasonic bath (Wisd Laboratory Instruments, WUC-A03H, Korea) (1 minute) $\left(\mathrm{W}_{1} / \mathrm{O}\right)$. This emulsion was then added drop-wise to $10 \mathrm{~mL}$ of PVA aqueous solution $\left(0.5 \%\right.$ w/v) using high-speed homogenizer (Ultraturrax T25, Janke \& Kunkel IKA ${ }^{\circledR}$ Labortechnik, Staufen, Germany) with $24.000 \mathrm{rpm}$ stirring for 1 minute $\left(\mathrm{W}_{1} / \mathrm{O} / \mathrm{W}_{2}\right)$. Ethyl acetate was evaporated at room temperature in 4 hours to obtain an aqueous dispersion which was finally centrifuged (11.000 rpm, $30 \mathrm{~min}, 4^{\circ} \mathrm{C}$ ) to collect the NPs (Rotina 420R, Hettich Zentrifugen, Germany). After washing twice, the NPs were resuspended in the distilled water and then frozen in freezer and lyophilized (Scanvac CoolSafePro Labogene, Denmark) to obtain a fine powder.

For the preparation of LAM-loaded PLGA NPs, the procedure started by adding $6 \mathrm{mg}$ LAM to $100 \mu \mathrm{L}$ PVA aqueous solution $(0.5 \% \mathrm{w} / \mathrm{v})$. PVA aqueous solution containing LAM was added drop-wise to $2 \mathrm{~mL}$ PLGA solution using ultrasonic bath (Wisd Laboratory Instruments, WUC-A03H, Korea) (1 minute) (W $\left.\mathrm{W}_{1} / \mathrm{O}\right)$. $2 \mathrm{~mL}$ of this emulsion was then added drop-wise to $10 \mathrm{~mL}$ of PVA aqueous solution $(0.5 \%, \mathrm{w} / \mathrm{v})$ under highspeed homogenizer (Ultraturrax T25, Janke \& Kunkel IKA ${ }^{\circledR}$ Labortechnik, Staufen, Germany) with $11.000 \mathrm{rpm}$ stirring for 1 minute $\left(\mathrm{W}_{1} / \mathrm{O} / \mathrm{W}_{2}\right)$. Ethyl acetate was evaporated at room temperature in 4 hours to obtain an aqueous dispersion which was finally centrifuged $\left(11.000 \mathrm{rpm}, 30 \mathrm{~min}, 4^{\circ} \mathrm{C}\right)$ to collect the NPs (Rotina 420R, Hettich Zentrifugen, Germany). After washing twice, the NPs were resuspended in the distilled water and then frozen in freezer and lyophilized (Scanvac CoolSafePro Labogene, Denmark) to obtain a fine powder.Formulation ingredients are presented in Table 3. 
Table 3. Formulation ingredients.

\begin{tabular}{cccc}
\hline Code & PLGA-1 & PLGA-2 & LAM \\
\hline A-Blank & $60 \mathrm{mg}$ & - & - \\
B-Blank & - & $60 \mathrm{mg}$ & - \\
C-Blank & $30 \mathrm{mg}$ & $30 \mathrm{mg}$ & - \\
D-Blank & $20 \mathrm{mg}$ & $40 \mathrm{mg}$ & - \\
E-Blank & $40 \mathrm{mg}$ & $20 \mathrm{mg}$ & - \\
A & $60 \mathrm{mg}$ & - & $6 \mathrm{mg}$ \\
B & - & $60 \mathrm{mg}$ & $6 \mathrm{mg}$ \\
C & $30 \mathrm{mg}$ & $30 \mathrm{mg}$ & $6 \mathrm{mg}$ \\
D & $20 \mathrm{mg}$ & $40 \mathrm{mg}$ & $6 \mathrm{mg}$ \\
E & $40 \mathrm{mg}$ & $20 \mathrm{mg}$ &
\end{tabular}

* Blank: Formulation without lamivudine, *LAM: Lamivudine, *PLGA-1: Acid terminated Resomer RG 504 H, *PLGA2: Ester terminated PLGA

\subsection{Characterization study}

\subsubsection{Particle size, Poly dispersity index, Zeta potential}

The particle size (PS) and polydispersity index (PDI) were measured using dynamic light scattering technique (DLS) on the Zetasizer Nano (Zetasizer Nano ZS, Malvern Instruments, Malvern, UK). PS and PDI of NPs prepared were measured by dispersing the formulation in distilled water and Zeta potential values were determined using the same instrument in a disposable folded capillary zeta cell, at room temperature $\left(25^{\circ} \mathrm{C}\right)$ and diluted with distilled water. For statistical analysis all samples were measured in triplicate and the average values and standard deviation of the measurements were calculated.

\subsubsection{High Performance Liquid Chromatography (HPLC)}

Entrapment efficiency (EE \%) and dissolution of each formulation was tested using HPLC (Shimadzu Corporation-20A, Kyoto, Japan) with reversed-phase NUKLEODUR ${ }^{\circledR}$ column $\left(4.6 \mathrm{~mm}^{*} 250 \mathrm{~mm}, \mathrm{C}_{18}\right.$ Gravity, 5 $\mu \mathrm{m})$ or the determination of LAM using a modified method. Mobile phase of the HPLC system was a mixture of water: methanol $(40: 60, \mathrm{v} / \mathrm{v})$ prepared daily, degassed by sonication and filtered through $0.45 \mu \mathrm{m}$ membrane filter just before testing. Flow rate was set at $0.8 \mathrm{~mL} / \mathrm{min}$ resulting in a run time of $10 \mathrm{~min}$ per sample and injection volume was $20 \mu \mathrm{L}$. $250 \mathrm{~nm}$ wavelength was used for detection and samples were analyzed at $30^{\circ} \mathrm{C}$. HPLC method used was validated for linearity, precision, accuracy and specificity [22].

\subsubsection{Entrapment efficiency}

LAM loading to PLGA NPs was determined by HPLC method described in the previous section. LAM, the active agent of PLGA NPs was evaluated by coordinate extraction of LAM from NPs. Lyophilize NPs (1 $\mathrm{mg}$ ) were precisely measured, $750 \mu \mathrm{L}$ acetone and $750 \mu \mathrm{L}$ distilled water was added and vortexed to break up the particles in the natural stage. Then this solution was diluted with distilled water in 1:10 ratio. Complete solution was filtered through $0.22 \mu \mathrm{m}$ polyamide filter and analyzed using HPLC. Entrapment efficiency was expressed as 'EE \%' following Equation $1[6,14]$.

$$
E E \%=\left[\frac{\text { Actual amount of LAM loaded in PLGA NPs }}{\text { Theoretical amount of LAM loaded in PLGA NPS }}\right] x 100
$$

\subsubsection{Dissolution study}

In vitro release of pure LAM and LAM from PLGA NPs was investigated over 144 hours using a dialysis membrane. NP containing $2 \mathrm{mg}$ LAM was placed in a cellulose acetate dialysis bag (Dialysis tubing cellulose membrane average flat width $33 \mathrm{~mm}$ [1.3 in.], molecular weight cut-off [MWCO]:14,000, D9652, SigmaAldrich, USA). After the addition of $1 \mathrm{~mL}$ of dissolution medium, the bag was sealed at both ends. Dialysis 
bag was then placed into an amber glass beaker containing $25 \mathrm{~mL}$ phosphate buffer $(\mathrm{pH} 6.8)$ at $37^{\circ} \mathrm{C} \pm 1^{\circ} \mathrm{C}$ as the dissolution medium under continuous stirring of $100 \mathrm{rpm}$ (IKA ${ }^{\circledR}$ Labortechnik RT 15 S000, Germany) [6]. The receptor compartment was closed to prevent evaporation of the dissolution medium. Samples were taken at regular time intervals to be $1 \mathrm{~mL}$ and the same volume was replaced with fresh dissolution medium. LAM concentration in the samples was quantified by HPLC method.

\subsubsection{Kinetic analysis of dissolution data}

Data obtained in the in vitro dissolution studies was further investigated for release kinetics using DDSolver software program. DDSolver computer program was used to shorten the calculation time, eliminate calculation errors and determine the correct release profile [26].

\subsection{Optimum formulation selection and characterization}

After preparation, the formulations were characterized as described in the above description and the optimum formulation was chosen. Characterization procedures in sections 4.3.1., 4.3.2., 4.3.3. and 4.3.4. were performed to the selected optimum formulation.

\subsubsection{Evaluation gastrointestinal stability of PLGA NPS}

The NPs prepared using hydrolytic degradable polymers are known to degrade over time. Effects of $\mathrm{pH}$ and temperature have a very significant effect on long-term stability [15]. Before testing the stability of PLGA NPs, solutions simulating gastrointestinal fluids were prepared. The solutions were $\mathrm{pH} 1.2$ buffer (Solution 1), intestinal fluid phosphate buffer solution (Solution 2, $\mathrm{pH}$ 6.8); phosphate buffer solution (Solution 3, pH 7.4); physiological serum $(0.9 \% \mathrm{NaCl})$ solution (Solution 4$)$ and distilled water.

All four solutions and distilled water were placed in a shaking water bath at a stirring speed of $50 \mathrm{rpm}$ at a temperature of $37^{\circ} \mathrm{C}$ to simulate the gastric medium. One set of B-coded LAM loaded PLGA formulation was prepared. Then, $1 \mathrm{~mL}$ of this dispersion was added to solutions incubated at $37 \pm 1^{\circ} \mathrm{C}$. Samples were collected after preincubation periods of 1, 2, 3, 9 and $24 \mathrm{~h}$. Then, the average PS and PDI of the NPs was determined with laser scattering.

\subsubsection{Thermal analysis (DSC)}

Physical state of formulations were characterized by differential scanning calorimetry (DSC) (DSC-60, Shimadzu Scientific Instruments, Columbia, MI, USA). Aluminum crucibles with $5 \mathrm{mg}$ samples were analyzed under nitrogen gas $(50 \mathrm{~mL} / \mathrm{min})$ and heating rate of $10^{\circ} \mathrm{C} / \mathrm{min}$ at a temperature range of 30 and $300^{\circ} \mathrm{C}$.

\subsubsection{FT-IR analysis}

FT-IR spectra were recorded using Shimadzu IR Prestige-21 (Shimadzu Corporation, Kyoto, Japan) at the wavelength range of $1500-500 \mathrm{~cm}^{-1}$.

\subsection{4. ${ }^{1} \mathrm{H}-\mathrm{NMR}$ analysis}

${ }^{1} \mathrm{H}-\mathrm{NMR}$ analyses were performed using UltraShieldTM CPMAS NMR (Brucker, Rheinstetten, Germany). Samples were prepared by dissolving formulations in deuterated chloroform $\left(\mathrm{CDCI}_{3}\right)$.

\subsection{Software program}

Microsoft Excel and DDSolver were employed for calculations.

Acknowledgements: Sanovel (İstanbul, Turkey) for providing lamivudine. The authors would also like to thank to Anadolu University, Faculty of Pharmacy, DOPNALAB for FT-IR and ${ }^{1} \mathrm{H}-\mathrm{NMR}$ facilities.

Author contributions: Concept - A.A.Ö.; Design - A.A.Ö., GYK; Supervision - A.A.Ö., Resource - A.A.Ö., G.Y.K.; Materials - A.A.Ö., G.Y.K.; Data Collection and/or Processing A.A.Ö., G.Y.K.; Analysis and/or Interpretation - A.A.Ö., G.Y.K.; Literature Search - A.A.Ö., G.Y.K.; Writing - A.A.Ö., G.Y.K.; Critical Reviews - A.A.Ö., G.Y.K.

Conflict of interest statement: The authors declare no conflict of interest. 


\section{REFERENCES}

[1] Jena AK, Nayak AK, De A, Mitra D, Samantha A. Development of lamivudine containing multiple emulsions stabilized by gum odina. Fut J Pharm Sci. 2018; 4: 71-79. [CrossRef]

[2] Alebouyeh M, Amini H. Rapid determination of lamivudine in human plasma by high-performance liquid chromatography. J Chromatogr B. 2015; 975: 40-44. [CrossRef]

[3] Johnson MA, Moore KHP, Yuen GJ, Bye A, Pakes GE. Clinical pharmacokinetics of lamivudine. Clin Pharmacokinet. 1999; 36(1): 41-66. [CrossRef]

[4] Sankara V, Nareshkumarb NP, Ajitkumarc GH, Penmetsad SD, Hariharane S. Comparative studies of lamivudinezidovudine nanoparticles for the selective uptake by macrophages. Curr Drug Deliv. 2012; 9: 506-514. [CrossRef]

[5] Öztürk AA, Çinar NI, Yenilmez E. Development of nano-sized ketoprofen lysine incorporated Eudragit ${ }^{\circledR}$ S100 nanomedicine by double emulsion solvent evaporation and in vitro characterization. J Pharm Pharmacogn Res. 2019; 7(1): 47-58.

[6] Öztürk AA, Martin Banderas L, Cayero Otero MD, Yenilmez E, Yazan Y. New approach to hypertension treatment: carvediol-loaded PLGA nanoparticles, preparation, in vitro characterization and gastrointestinal stability. Lat Am J Pharm. 2018; 37(9): 1730-1741.

[7] Makadia HK, Siegel SJ. Poly Lactic-co-glycolic acid (PLGA) as biodegradable controlled drug delivery carrier. Polym. 2011; 3: 1377-1397. [CrossRef]

[8] Houchin ML. Topp EM. Chemical degradation of peptides and proteins in PLGA: A Review of Reactions and Mechanisms. J Pharm Sci. 2007; 97(7): 2395-2404. [CrossRef]

[9] Rao JP, Geckeler KE. Polymer nanoparticles: Preparation techniques and size-control parameters. Pro Polym Sci. 2011; 36(7): 887-913. [CrossRef]

[10] Wang B, Chen GQ, Mao ZW, Zhang YY, Yu DH, Gao CY. Preparation and cellular uptake of PLGA particles loaded with lamivudine. Chin. Sci. Bull. 2012; 57(31): 3985-3993.

[11] Bhattacharjee S. DLS and zeta potential - What they are and what they are not? J Control Release. 2016; 235: 337-351. [CrossRef]

[12] Kırımlığlu GY, Menceloğlu Y, Erol K, Yazan Y. In vitro/in vivo evaluation of gamma-aminobutyric acid-loaded $\mathrm{N}, \mathrm{N}$-dimethylacrylamide-based pegylated polymeric nanoparticles for brain delivery to treat epilepsy. J Microencapsul. 2016; 33(7): 625-635. [CrossRef]

[13] Öztürk AA, Yenilmez E, Yazan Y. Dexketoprofen trometamol-loaded Eudragit ${ }^{\circledR}$ RL 100 nanoparticle formulation, characterization and release kinetics. Acta Pharm Sci. 2018; 57(1): 69-84. [CrossRef]

[14] Huang W, Zhang C. Tuning the size of poly(lactic-co-glycolic acid) (PLGA) nanoparticles fabricated by nanoprecipitation. Biotechnol J. 2018; 13(1): 1-19. [CrossRef]

[15] Öztürk AA, Martin-Banderas L, Cayero Otero MD, Yenilmez E, Şenel B, Yazan Y. Dexketoprofen trometamol-loaded poly-lactic-co-glycolic acid (PLGA) nanoparticles: Preparation, in vitro characterization and cyctotoxity. Trop J Pharm Res. 2019; 18(1): 1-11. [CrossRef]

[16] Danaei M, Dehghankhold M, Ataei S, Davarani FH, Javanmard R, Dokhanib A, Khorasani S, Mozafari MR. Impact of particle size and polydispersity index on the clinical applications of lipidic nanocarrier systems. Pharmceutics. 2018; 10(57): 1-17. [CrossRef]

[17] Öztürk AA, Gündüz AB, Özışık O. Supervised machine learning algorithms for evaluation of solid lipid nanoparticles and particle size. Comb Chem High Throughput Screen. 2018; 21(9): 693-699. [CrossRef]

[18] Csaba N, Garcia-Fuentes M, Alonso MJ. The performance of nanocarriers for transmucosal drug delivery. Expert Opin Drug Deliv. 2006; 3(4): 463-478. [CrossRef]

[19] Chigumira W, Maposa P, Gadaga LL, Dube A, Tagwireyi D, Maponga CC. Preparation and evaluation of pralidoxime-loaded PLGA nanoparticles as potential carriers of the drug across the blood brain barrier. J Nanomater. 2015; 692672: 1-5. [CrossRef] 
[20] Honary S, Zahir F. Effect of zeta potential on the properties of nano-drug delivery systems - a review (Part 2). Trop J Pharma Res. 2013; 12(2): 265-273. [CrossRef]

[21] Quaglia F, Ostacolo L, Mazzaglia A, Villari V, Zaccaria D, Sciortino MT. The intracellular effects of non-ionic amphiphilic cyclodextrin nanoparticles in the delivery of anticancer drugs. Biomaterials. 2009; 30(3): 374-382. [CrossRef]

[22] de Jesus Gomes, Lunardi CN, Caetano FH, Lunardi LO, da Hora Machado AE. Phagocytosis of PLGA microparticles in rat peritoneal exudate cells: a time-dependent study. Microsc Microanal. 2006; 12(5): 399-405. [CrossRef]

[23] Kamala G, Vadrewu S, Valli N. Development and validation of RP-HPLC method for simultaneus estimation of lamivudine and zidovudine in bulk. Int J Curr Pharm Res. 2016; 8(1): 28-33.

[24] Öztürk AA, Yenilmez E, Yazan Y. Development and validation of high performance liquid chromatography (HPLC) modified method for dexketoprofen trometamol. Eur Int J Sci Tec. 2017; 6(5): 33-41

[25] Kırımlıŏlu GY, Yazan Y. Determination of gamma-aminobutyric acid by HPLC: Its application to polymeric nanoparticles and stability studies. Int J Develop Res. 2016; 6(6): 8277-8282.

[26] Chen G, Wen J. Poly(lactic-co-glycolic acid) based double emulsion nanoparticle as a carrier system to deliver glutathione sublingually. J Biomed. 2018; 3: 50-59. [CrossRef]

[27] Zhang Y, Huo M, Zhou J, Zou A, Li W, Yao C, Xie S. DDSolver: An add-in program for modeling and comparison of drug dissolution profiles. The AAPS J. 2010; 12: 263-271. [CrossRef]

[28] Basu T, Pal B, Singh S. Fabrication of core-shell PLGA/PLA-pNIPAM nanocomposites for improved entrapment and release kinetics of antihypertensive drugs. Particuology. 2018; 40: 169-176. [CrossRef]

[29] Peter Christoper GV, Vijaya Raghavan C, Siddharth K, Siva Selva Kumar M, Hari Prasad R. Formulation and optimization of coated PLGA - Zidovudine nanoparticles using factorial design and in vitro in vivo evaluations to determine brain targeting efficiency. Saudi Pharm J. 2013; 22(2): 133-40. [CrossRef]

[30] Öztürk AA, Yenilmez E, Şenel B, Arslan R, Yazan Y. Dexketoprofen trometamol-loaded Kollidon® SR and Eudragit® RS 100 polymeric nanoparticles: Formulation and in vitro-in vivo evaluation. Lat Am J Pharm. 2017; 36(11): $2153-2165$.

[31] Singh AV, Nath LK. Evaluation of compatibility of tablet excipients and novel synthesized polymer with lamivudine. J Therm Anal Calorim. 2012; 108(1): 263-267. [CrossRef]

[32] Pang J, Luan Y, Li F, Cai X, Du J, Li Z. Ibuprofen-loaded poly(lactic-co-glycolic acid) films for controlled drug release. Int J Nanomedicine. 2011; 6: 659-65. [CrossRef]

[33] Öztürk AA, Güven UM, Yenilmez E, Şenel B. Effects of different derivatives of eudragit polymer on entrapment efficiency, in vitro dissolution, release kinetics and cell viability results on extended release flurbiprofen loaded nanomedicines. Lat Am J Pharm. 2018; 37(10): 1981-1992.

[34] Kırımlığlu GY, Yazan Y, Erol K, Ünel ÇÇ. Gamma-aminobutyric acid loaded halloysite nanotubes and in vitro-in vivo evaluation for brain delivery. Int J Pharm. 2015; 495(2): 816-826. [CrossRef]

[35] Yenilmez E, Kırımlıŏlu GY, Şenel B, Başaran E. Preparation, characterization and in vitro evaluation of dirithromycin loaded Eudragit@ RS 100 nanoparticles for topical application. Lat Am J Pharm. 2017; 36(11): 2203-2212.

[36] Pandey G, Yadav SK, Mishra B. Preparation and characterization of isoniazid and lamivudine co-loaded polymeric microspheres. Artif Cells Nanomed Biotechnol. 2016; 44(8): 1867-1877. [CrossRef]

[37] Singh G, Kaur T, Kaur R, Kaur A. Recent biomedical applications and patents on biodegradable polymer- PLGA. Int J Pharmacol Pharm Sci. 2014: 1(2): 30-42.

[38] Roy BN, Singh GP, Srivastava D, Aher UP, Patil SU. A stereoselective process for preparation of 1,3-oxathiolane nucleosides. 2013; Patent number: WO2013021290A1. 